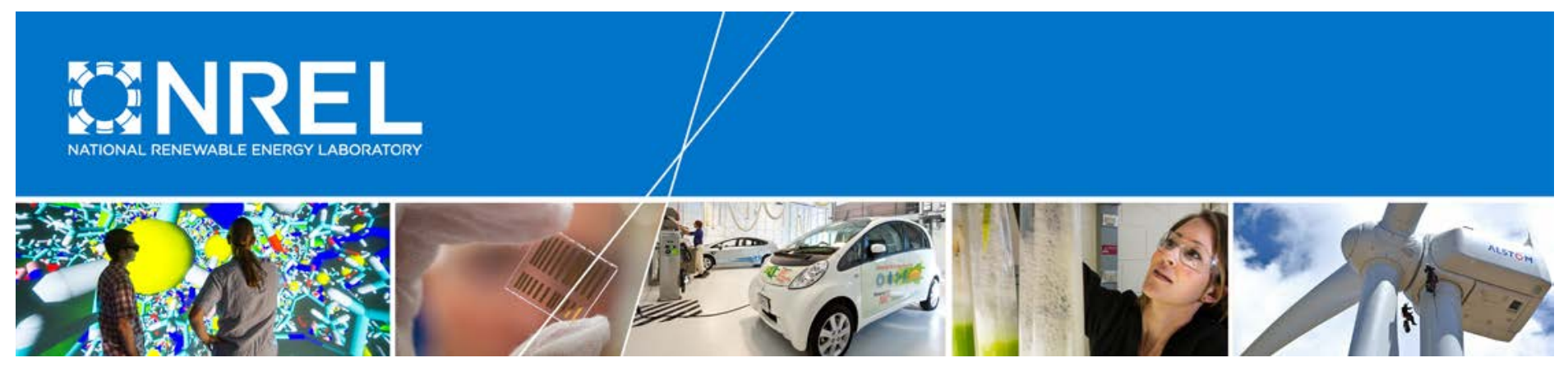

\title{
Investigation of Bearing Axial Cracking: Benchtop and Full- Scale Test Results
}

Jonathan Keller

National Renewable Energy Laboratory

Benjamin Gould and Aaron Greco Argonne National Laboratory

NREL is a national laboratory of the U.S. Department of Energy Office of Energy Efficiency \& Renewable Energy Operated by the Alliance for Sustainable Energy, LLC

This report is available at no cost from the National Renewable Energy Laboratory (NREL) at www.nrel.gov/publications.

Technical Report

NREL/TP-5000-67523

Revised January 2019

Contract No. DE-AC36-08G028308 


\section{Investigation of Bearing Axial Cracking: Benchtop and Full- Scale Test Results}

Jonathan Keller

National Renewable Energy Laboratory

Benjamin Gould and Aaron Greco Argonne National Laboratory

Prepared under Task No. WEPG.10346.25.01.02

NREL is a national laboratory of the U.S. Department of Energy Office of Energy Efficiency \& Renewable Energy Operated by the Alliance for Sustainable Energy, LLC

This report is available at no cost from the National Renewable Energy Laboratory (NREL) at www.nrel.gov/publications.

National Renewable Energy Laboratory 15013 Denver West Parkway Golden, CO 80401

303-275-3000 • www.nrel.gov

\section{Technical Report}

NREL/TP-5000-67523

Revised January 2019

Contract No. DE-AC36-08GO28308 


\section{NOTICE}

This report was prepared as an account of work sponsored by an agency of the United States government. Neither the United States government nor any agency thereof, nor any of their employees, makes any warranty, express or implied, or assumes any legal liability or responsibility for the accuracy, completeness, or usefulness of any information, apparatus, product, or process disclosed, or represents that its use would not infringe privately owned rights. Reference herein to any specific commercial product, process, or service by trade name, trademark, manufacturer, or otherwise does not necessarily constitute or imply its endorsement, recommendation, or favoring by the United States government or any agency thereof. The views and opinions of authors expressed herein do not necessarily state or reflect those of the United States government or any agency thereof.

This report is available at no cost from the National Renewable Energy Laboratory (NREL) at www.nrel.gov/publications.

Available electronically at SciTech Connect http:/www.osti.gov/scitech

Available for a processing fee to U.S. Department of Energy and its contractors, in paper, from:

U.S. Department of Energy

Office of Scientific and Technical Information

P.O. Box 62

Oak Ridge, TN 37831-0062

OSTI http://www.osti.gov

Phone: 865.576.8401

Fax: 865.576.5728

Email: reports@osti.gov

Available for sale to the public, in paper, from:

U.S. Department of Commerce

National Technical Information Service

5301 Shawnee Road

Alexandria, VA 22312

NTIS http://www.ntis.gov

Phone: 800.553 .6847 or 703.605 .6000

Fax: 703.605.6900

Email: orders@ntis.gov 


\section{Errata}

This report, originally published in August 2017, was revised in January 2019. The equations for velocities originally shown in Figure 7 were removed, as they no longer correspond to the same set of equations in NREL/TP-5000-70639. The discrepancy was caused by a change in the frame of reference for the roller speed measurement. The figure itself was also updated to match a similar figure in NREL/TP-5000-70639. Additionally, the figure caption was updated to indicate that the roller speed shown in the figure was from a previous experiment, not the work described in this report. 


\section{Acknowledgments}

This work was supported by the U.S. Department of Energy under Contract No. DE-AC3608GO28308 with the National Renewable Energy Laboratory and under Contract No. DE-AC0206CH1 1357 with Argonne National Laboratory. Funding for the work was provided by the DOE Office of Energy Efficiency and Renewable Energy, Wind Energy Technologies Office. 


\section{Table of Contents}

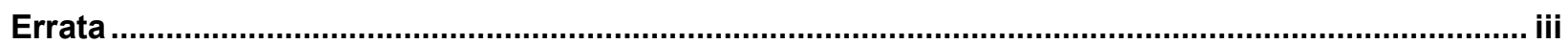

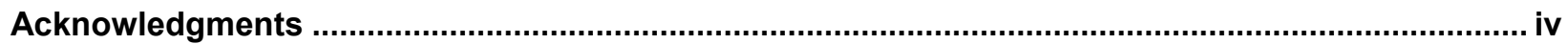

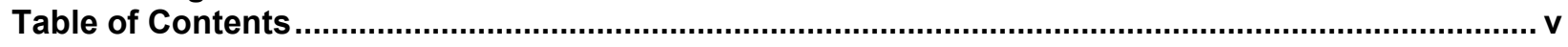

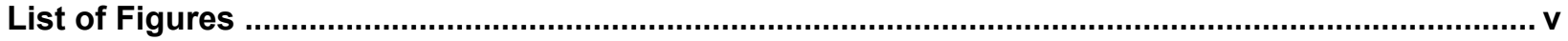

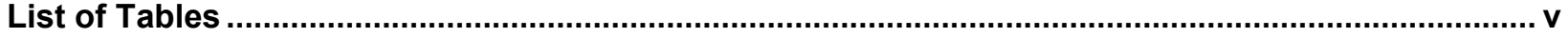

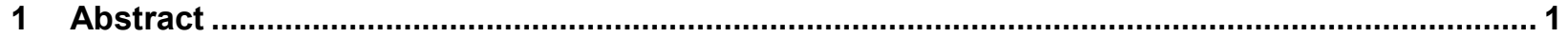

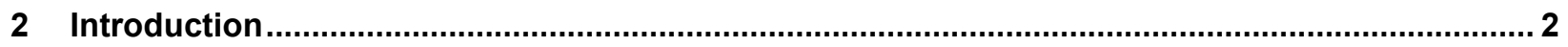

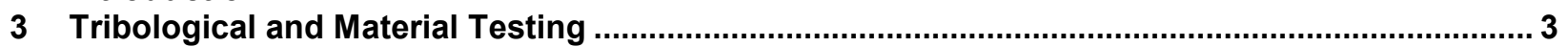

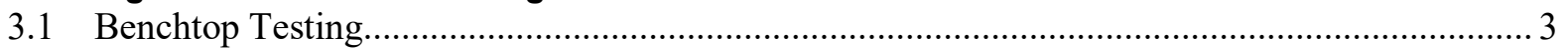

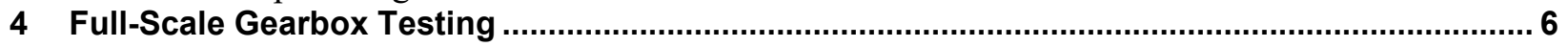

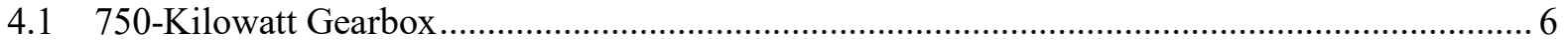

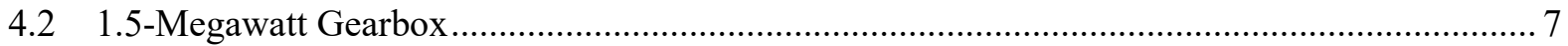

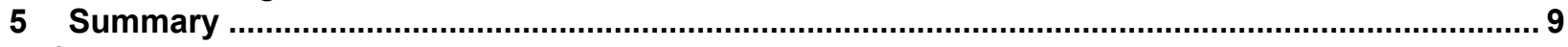

References

\section{List of Figures}

Figure 1. Micro Pitting Rig tribological benchtop test rig overall view (a) and view of the test housing showing the three-ring-on-roller configuration (b) [5]

Figure 2. Benchtop test sample roller post-test; top view of roller race with spall (a) and

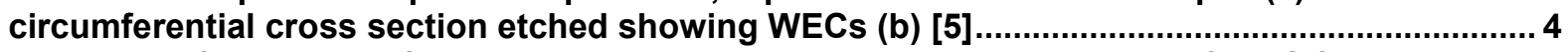

Figure 3. Plot of the results from the benchtop tests showing the threshold of WEC formation with respect to cumulative frictional heat energy [5]

Figure 4. Braking event speed and torque event (left) and resulting bearing roller contact stress and sliding indicator (right) ....................................................................................................... 6

Figure 5. Grid-loss event speed and torque event (left) and resulting bearing roller contact stress

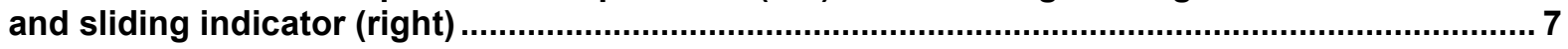

Figure 6. Normal power production speed and torque event (left) and resulting bearing roller contact stress and sliding indicator (right) .................................................................................. 7

Figure 7. Bearing roller sliding velocities (left) and measurements (right). Illustration (right) by $S K F[17]$

Figure 8. High-speed-shaft instrumentation package. 8

\section{List of Tables}

Table 1. Benchtop Test Conditions and Results with Calculated Cumulative Frictional Energy....... 4 


\section{Abstract}

The most common failure mode in wind turbine gearboxes is axial cracking in intermediate and high-speed-stage bearings, also commonly called white-etching cracks (WECs). Although these types of cracks have been reported for over a decade, the conditions leading to WECs, the process by which this failure culminates, and the reasons for their apparent prevalence in wind turbine gearboxes are all highly debated. This paper summarizes the state of a multipronged research effort to examine the causes of WECs in wind turbine gearbox bearings. Recent efforts have recreated WECs on a benchtop test rig in highly loaded sliding conditions, wherein it was found that the formation of a dark etching microstructure precedes the formation of a crack, and a crack precedes the formation of white-etching microstructure. A cumulative frictional sliding energy criterion has been postulated to predict the presence of WECs. Bearing loads have also been measured and predicted in steady state and transient drivetrain operations in dynamometer testing. In addition, both loads and sliding at full scale will be measured in planned uptower drivetrain testing. If the cumulative frictional sliding energy is the dominant mechanism that causes WECs, understanding the amount of frictional sliding energy that wind turbine bearings are subjected to in typical operations is the next step in the investigation. If highly loaded sliding conditions are found uptower, similar to the examined benchtop levels, appropriate mitigation solutions can be examined, ranging from new bearing coatings and improved lubricants to changes in gearbox designs and turbine operations. 


\section{Introduction}

Failures in gearbox bearings have been the primary source of reliability issues for wind turbine drivetrains, leading to costly downtime and unplanned maintenance. The most common failure mode is attributed to so-called axial cracks or white-etching cracks (WECs), which primarily affect the intermediate and high-speed-stage bearings. According to the Gearbox Reliability Database maintained by the National Renewable Energy Laboratory, bearing failures account for over $60 \%$ of all failures, and axial cracking represents over $70 \%$ of all bearing failures. "Axial crack" refers to the orientation of the crack as it appears on the raceway of the bearing inner ring. These cracks tend to propagate to spalls or lead to a complete splitting of the ring. Upon crosssectional and metallographic analysis of the cracked bearing, the microstructure of the steel surrounding the crack is observed to have experienced alterations. The altered steel microstructure is evident by how the material responds to chemical etching in which the alteration appears white compared to the unaltered material, lending to the name "white-etching cracks." These failures in wind turbine bearings occur well before the design life as predicted by the standard L10 life defined by the International Organization for Standardization and American Bearing Manufacturers Association. Furthermore, the morphology of the crack and alteration of the microstructure is not consistent with typical features observed in classical rolling contact fatigue, namely: butterflies and white-etching bands. This inconsistency indicates that the WEC failures are either the result of drivers beyond the load used in calculating L10 rolling contact fatigue bearing life, or the load in wind turbine bearings are not well understood and exceed predicted levels.

Considerable research efforts have focused on understanding the possible root causes of WECs, which have included: high strain rates [1-3], hydrogen embrittlement [4,5], bearing skidding and sliding [6-8], inclusions [2,3,5,9,10], bearing assembly, corrosion fatigue cracking [11], and electrical current $[12,13]$. To date, there is little consensus on the root causes of WECs in wind turbine bearings. It is the aim of the current study to evaluate the causes of WECs in wind turbine bearings with a multipronged approach that includes: a system-level analysis to measure the real operating conditions in a wind turbine gearbox and the contact conditions that exist in field-representative operations, and a tribological and materials analysis to understand how bearing steel responds at a microstructural level to a range of contact conditions. The current work will focus on the influence of skidding/sliding between the bearing rolling element and the raceway. 


\section{Tribological and Material Testing}

To provide a platform to readily evaluate the range of possible root causes of WECs cited in the introduction, a tribological benchtop rig is utilized that is capable of replicating the contact conditions that are experienced between a rolling element and raceway in a wind turbine gearbox bearing. The benchtop rig is capable of inducing a range of highly controllable contact conditions, including load, slide-to-roll ratio (SRR), speed, and temperature. The rig is also configurable to test nonstandard conditions like electrical currents across the contact. The advantage of conducting tests on a benchtop rig is that it not only accelerates the ability to evaluate a range of conditions on WEC formation, but also enables detailed study of the evolution of the failure initiation and propagation through post-test microstructural analysis of the test samples.

\subsection{Benchtop Testing}

The tribological test rig used in this study is a PCS Instruments Micro Pitting Rig, shown in Figure 1, which provides a three-ring-on-roller splash-lubricated line contact and allows for testing at customizable user-specified conditions: SRRs ranging from pure rolling to pure sliding, at loads ranging from 0.5 gigapascal $(\mathrm{GPa})$ to $3 \mathrm{GPa}$, and at lubricant temperatures in excess of $100^{\circ} \mathrm{C}$.

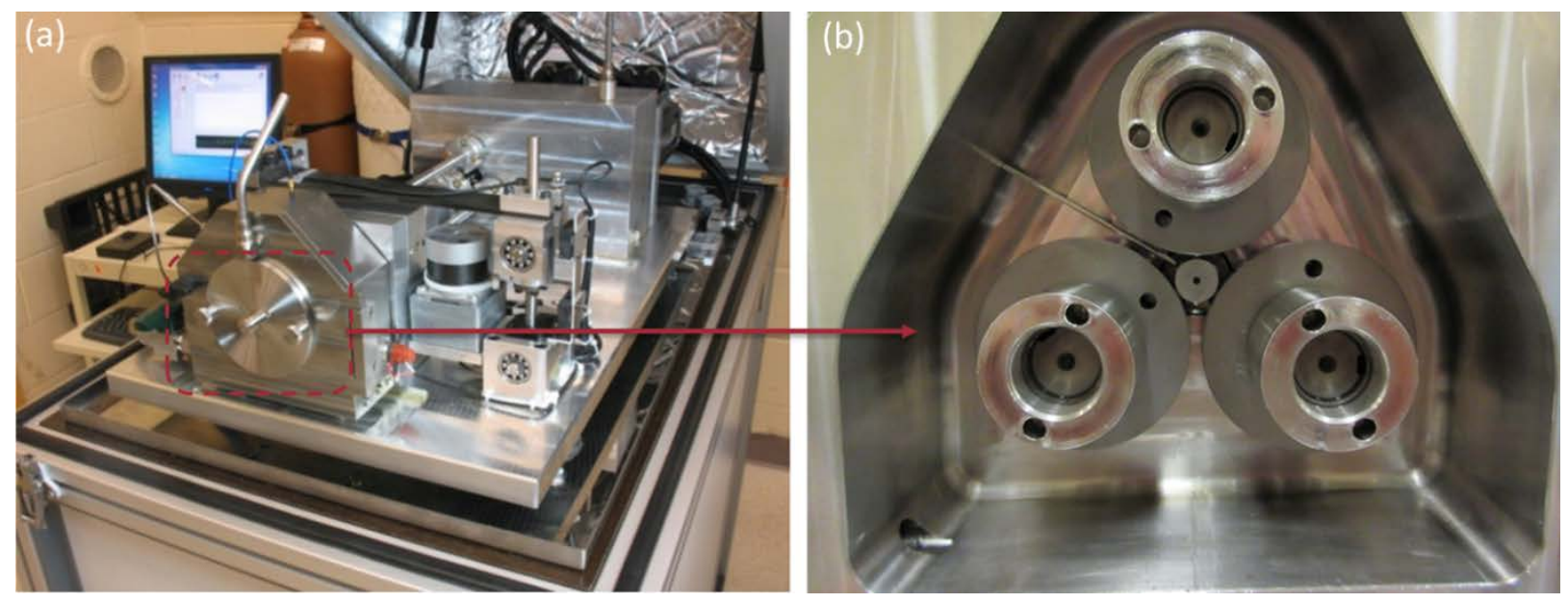

Figure 1. Micro Pitting Rig tribological benchtop test rig overall view (a) and view of the test housing showing the three-ring-on-roller configuration (b) [5]

The lubricant used in this study is a fully formulated gear oil mix consisting of Group I+IV semisynthetic base stock, viscosity-grade 68 . This specific gear oil formulation has been shown in several studies to readily form WECs. It is used in this current study to demonstrate which range of contact conditions would lead to WEC formation. The test samples are made of American Iron and Steel Institute 52100 through hardened, tempered, martensitic steel for both the rollers and rings with a Rockwell $\mathrm{C}$ hardness of 60 and 63, respectively. Experiments were conducted with a range of loads, speeds, and SRR conditions, as shown in Table 1. 
Table 1. Benchtop Test Conditions and Results with Calculated Cumulative Frictional Energy

\begin{tabular}{cccccccc}
\hline Test & $\begin{array}{c}\text { Normal } \\
\text { Load } \\
(\mathbf{N})\end{array}$ & $\begin{array}{c}\text { Contact } \\
\text { Stress } \\
(\mathbf{G P a})\end{array}$ & $\begin{array}{c}\text { Rolling } \\
\text { Speed } \\
(\mathbf{m} / \mathbf{s})\end{array}$ & $\begin{array}{c}\text { SRR } \\
\mathbf{( \% )}\end{array}$ & $\begin{array}{c}\text { Contact } \\
\text { Cycles } \\
\left(\mathbf{x 1 0 ^ { 6 } )}\right.\end{array}$ & WECs? & $\begin{array}{c}\text { E } \\
\text { (megajoule) }\end{array}$ \\
\hline 1 & 500 & 1.9 & 1 & -30 & 38.2 & Yes & 8.04 \\
2 & 500 & 1.9 & 1 & +30 & 18.2 & No & 3.32 \\
3 & 500 & 1.9 & 1 & -5 & 100 & No & 3.52 \\
4 & 500 & 1.9 & 1 & +5 & 34.5 & No & 1.03 \\
5 & 40 & 0.5 & 3.4 & -30 & 100 & No & 2.89 \\
6 & 135 & 1.0 & 3.4 & -30 & 100 & Yes & 7.93 \\
7 & 300 & 1.5 & 3.4 & -30 & 100 & Yes & 13.14 \\
8 & 500 & 1.9 & 3.4 & -30 & 42 & Yes & 9.70 \\
9 & 500 & 1.9 & 1 & -30 & 20 & No & 4.63 \\
10 & 500 & 1.9 & 1 & -30 & 30 & Yes & 6.26 \\
\hline
\end{tabular}

Tests were concluded when a spall failure occurred, as indicated by the measured vibration between the roller and top ring. If no failure occurred, the test was stopped at 100 million cycles. To determine if WECs were formed, the roller sample was sectioned after the test and exposed to a Nital etchant, as shown in Figure 2.
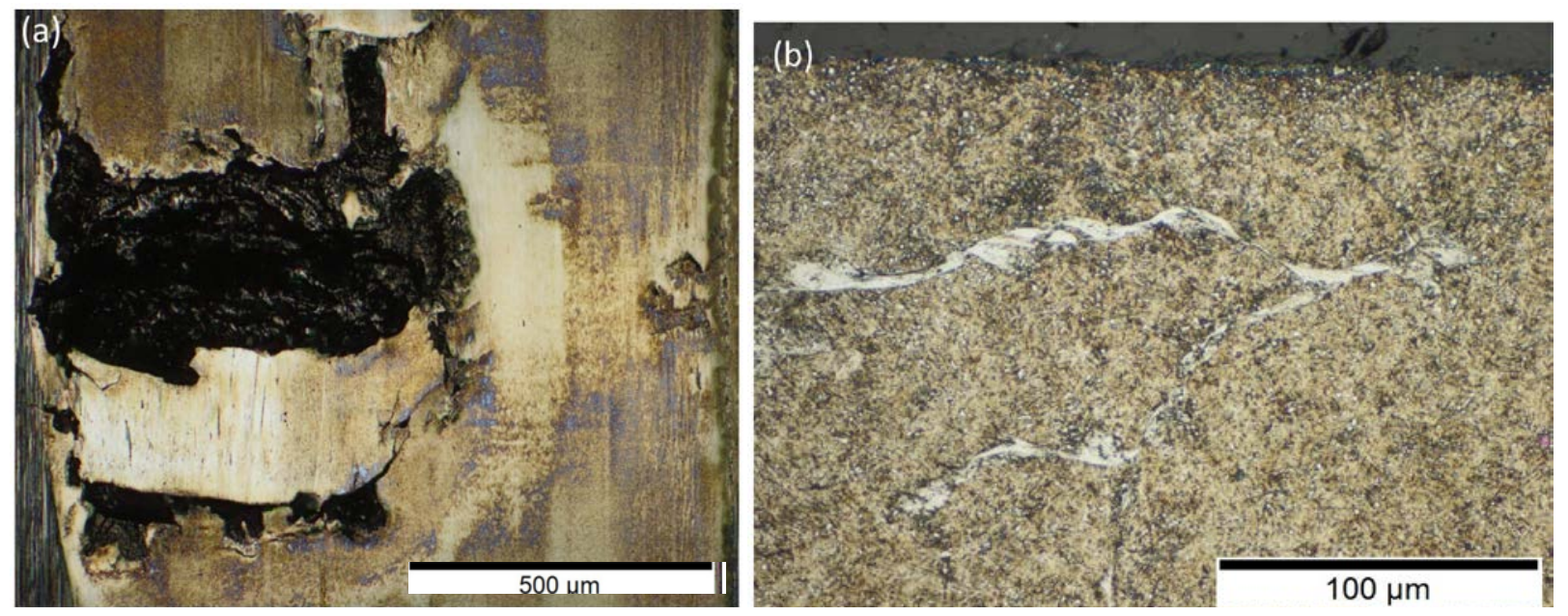

Figure 2. Benchtop test sample roller post-test; top view of roller race with spall (a) and circumferential cross section etched showing WECs (b) [5]

The first four tests, $1-4$, show the dependence of WEC formation under a range of SRR conditions between $+/-5 \%$ and $+/-30 \%$. Of these four tests, only the test performed at $-30 \% \mathrm{SRR}$ resulted in WEC formation. The next four tests, 5-8, show the WEC dependence under a range of load conditions between 0.5 and $1.9 \mathrm{GPa}$. Only the test at $0.5 \mathrm{GPa}$ did not result in a WEC within the 100-million-contact-cycle duration. The final two tests, 9-10, showed the effect of test duration between 20 and 30 million cycles. Both tests were stopped deliberately at the respective contact cycles. The test at 20 million cycles did not result in WECs, whereas the test that stopped at 30 million cycles did. To correlate these tests using one parameter, a value was calculated to 
represent the cumulative frictional heat energy, $E$, generated during each test, as demonstrated in Eq. 1, where $\Delta V$ is the sliding speed (the difference between the velocity of the ring and the velocity of the roller at the contact), $\mu$ is the average measured friction coefficient, $N$ is the normal load, and $t$ is the total testing time:

$$
E=\frac{3}{2} \Delta V \mu N t
$$

Considering this energy parameter, the results of the 10 tests are plotted with respect to the occurrence and number of WECs observed in the roller sample post-test as shown in Figure 3. This plot shows a threshold of WEC formation with respect to the cumulative frictional heat energy parameter. The magnitude of this energy parameter is likely to only be specific to the current benchtop test configuration, materials, lubricant, and conditions; therefore, it is not necessarily directly translatable to the full-scale application. However, the premise is that frictional heat resulting from high-load and sliding contact is likely one possible driver for WEC formation in wind turbine gearbox bearings. It is not evident from these results what physical connection friction energy has on WEC formation, as it could be a response of the material to the heat input or a response of the lubricant resulting in hydrogen liberation, leading to material embrittlement. These physical responses will be the focus of future research. However, the likelihood of high-load and sliding contact conditions is considered at the full scale in the following sections of this report.

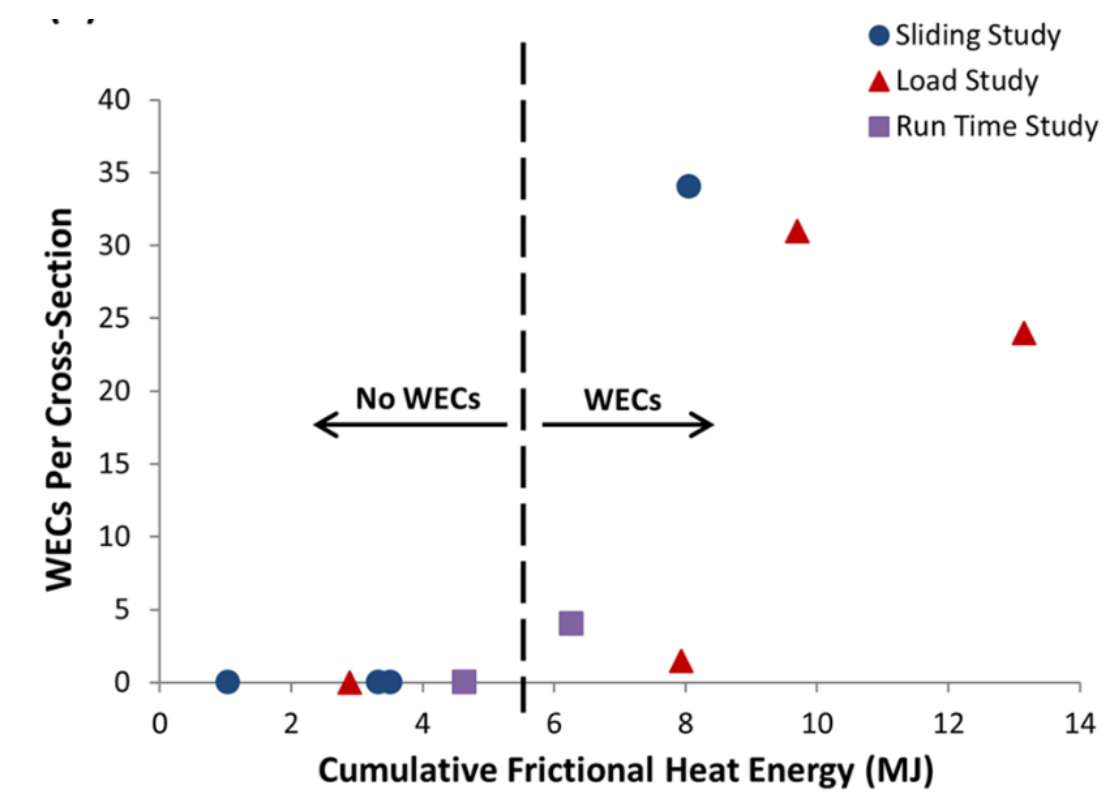

Figure 3. Plot of the results from the benchtop tests showing the threshold of WEC formation with respect to cumulative frictional heat energy [5] 


\section{Full-Scale Gearbox Testing}

Currently, there is only speculation, rather than strong evidence, that high-load and sliding contact conditions in excess of the proposed criteria occur during typical wind turbine operations. In recognition of this, full-scale gearbox testing is required to determine the causal factors that result in bearing roller sliding and high loads. That is, which plant and turbine operations, configurations, and situations result in the bearing roller sliding, load, and tribological conditions sufficiently often enough to exceed the cumulative frictional heat energy? A secondary goal is to examine the presence of additional tribological factors in operation, such as temperatures, stray currents, and moisture also suspected of relating to WECs. These full-scale test results might also inform additional cases for the current benchtop tests; for example, if the loads, sliding, or other tribological factors measured were well in excess of or well below those already tested.

\subsection{0-Kilowatt Gearbox}

Field-representative dynamometer tests of the Gearbox Reliability Collaborative 750-kilowatt drivetrain were conducted [14] and high-speed-shaft and bearing loads were examined. Bearing roller speed was not measured. Steady-state operations were examined first [15], whereas more recently, bearing contact stresses and roller sliding were examined during normal power production, braking, and grid-loss events [16]. As shown in Figure 4 through Figure 6, roller sliding was evident within the bearing outer race loads, although without dedicated roller speed instrumentation its magnitude was unknown.
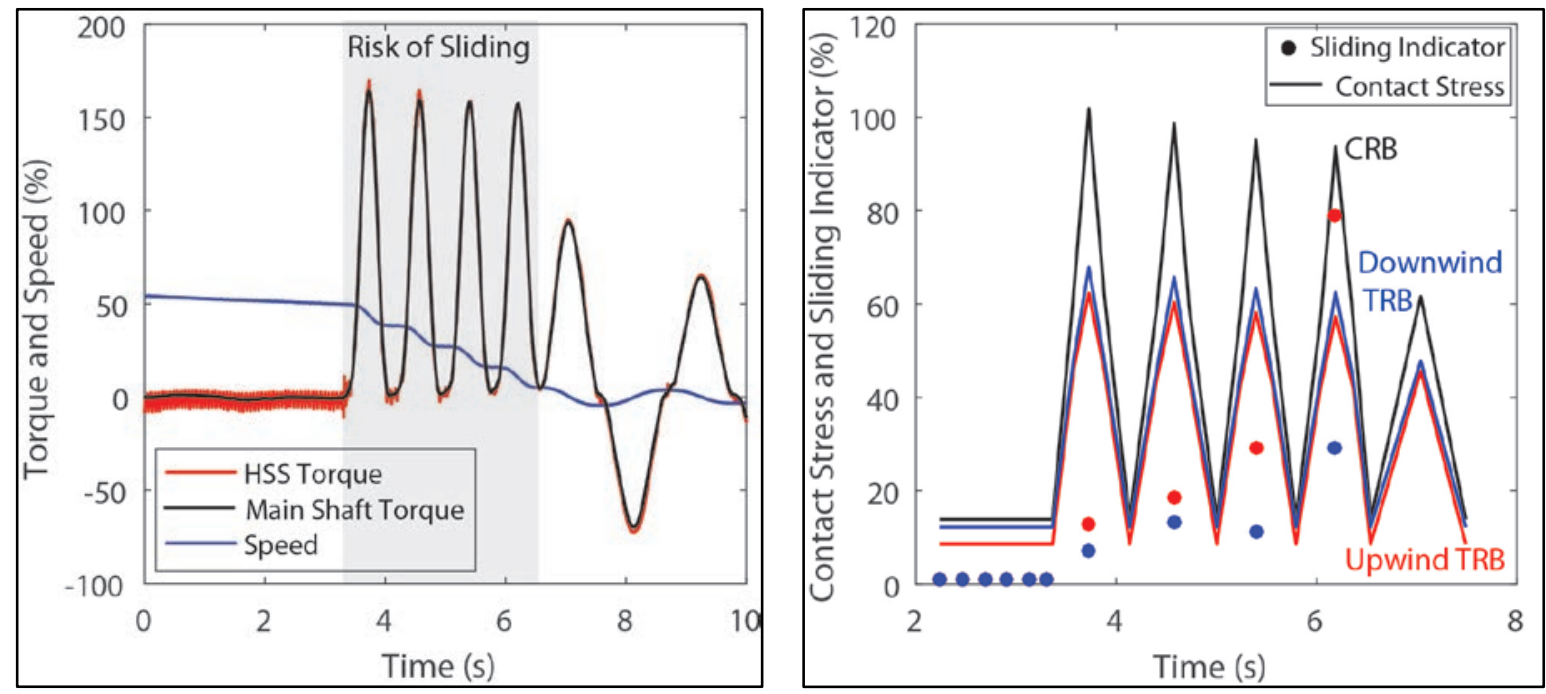

Figure 4. Braking event speed and torque event (left) and resulting bearing roller contact stress and sliding indicator (right) 

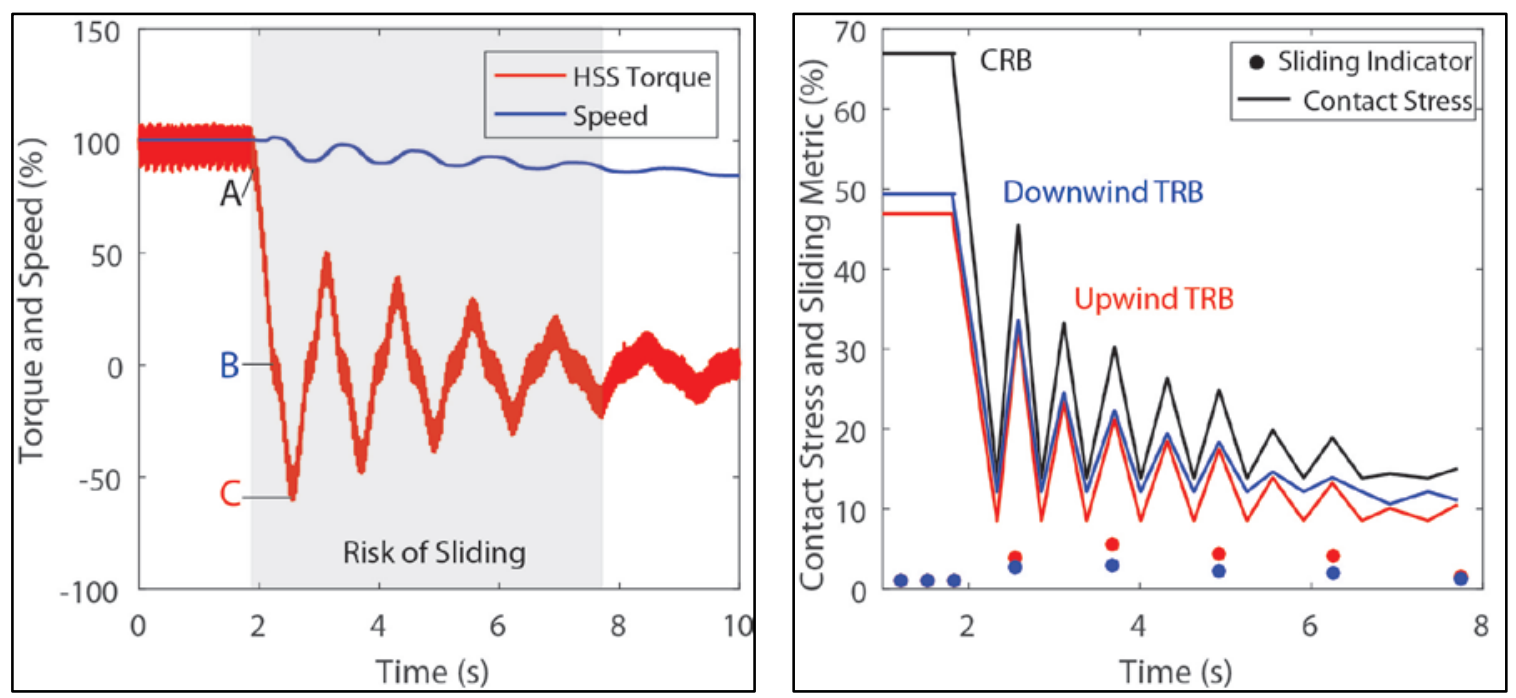

Figure 5. Grid-loss event speed and torque event (left) and resulting bearing roller contact stress and sliding indicator (right)
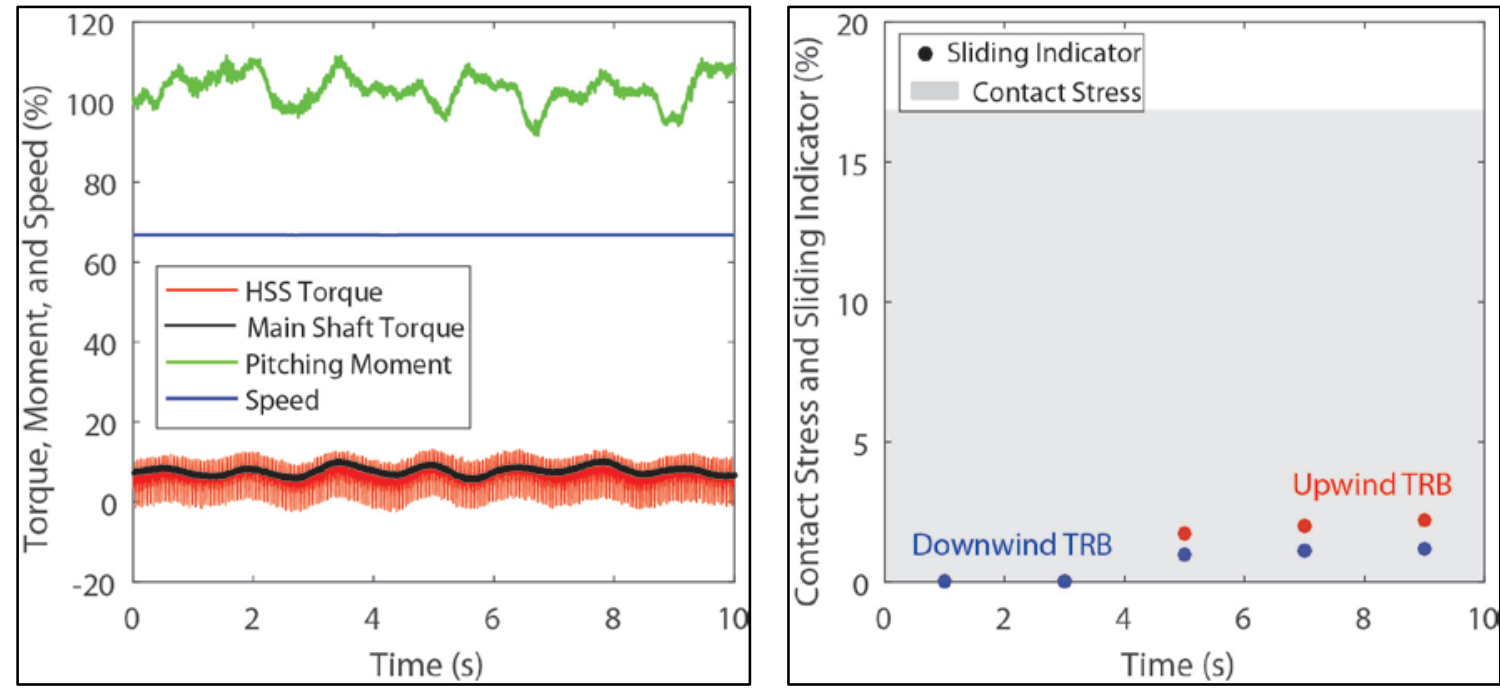

Figure 6. Normal power production speed and torque event (left) and resulting bearing roller contact stress and sliding indicator (right)

\subsection{5-Megawatt Gearbox}

Because of the importance of sliding to the formation of WECs, both loads and sliding will be measured in upcoming tests. Sliding must be measured, because it cannot be predicted with sufficient accuracy - especially in the highly dynamic wind turbine gearbox application. As shown in Figure 7, bearing roller sliding can be determined by the rotational speed of the shaft $\left(\omega_{s}\right)$, bearing cages $\left(\omega_{c}\right)$, and bearing rolling elements $\left(\omega_{r}\right)$. Of all of these speeds, by far the most difficult to measure is the rolling element speed. Patented instrumentation from SKF will measure it by sensing the change in voltage in a nearby inductive coil as a magnetized roller rotates in operation [17]. 

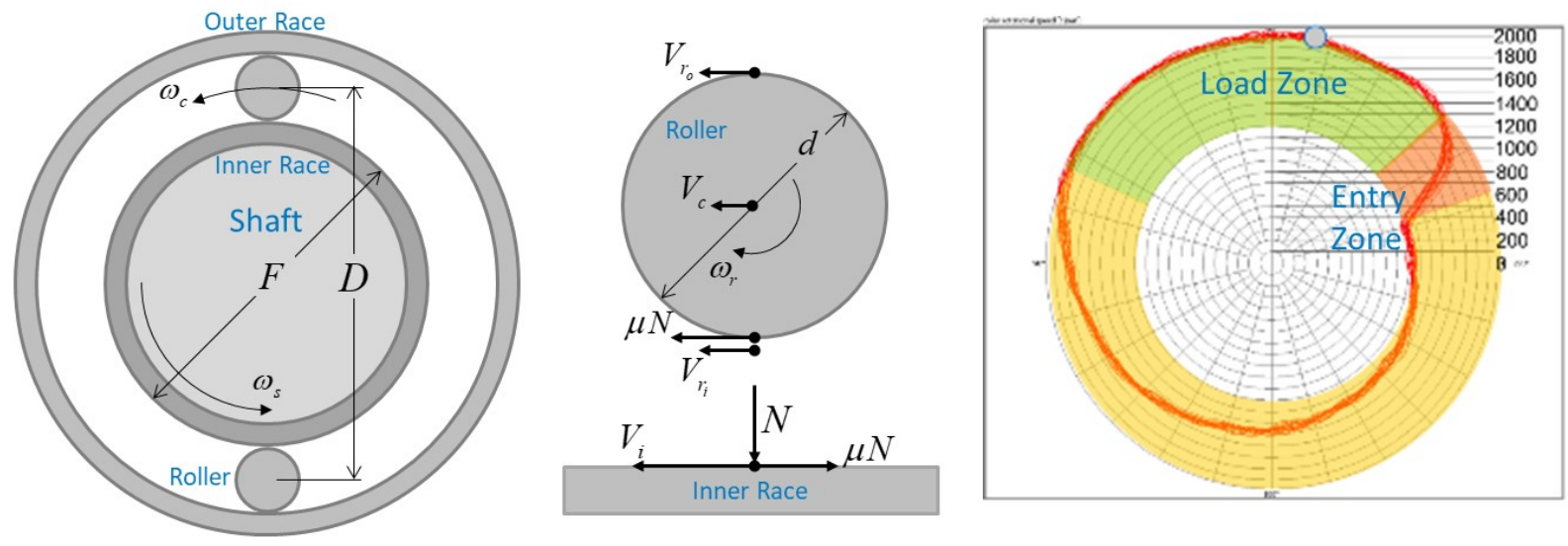

Figure 7. Bearing roller sliding velocities (left) and previous measurements (right). Illustration (right) by SKF [17]

A commercial gearbox will be instrumented and installed in the GE 1.5 SLE turbine at the National Wind Technology Center in late 2017 [18]. As shown in Figure 8, the high-speed-shaft cylindrical roll bearing speeds will be measured along with torque, bending moments, and other tribological factors such as temperatures, humidity, stray current, and water-in-oil content, and correlated to the turbine and grid conditions over a range of controlled operations.

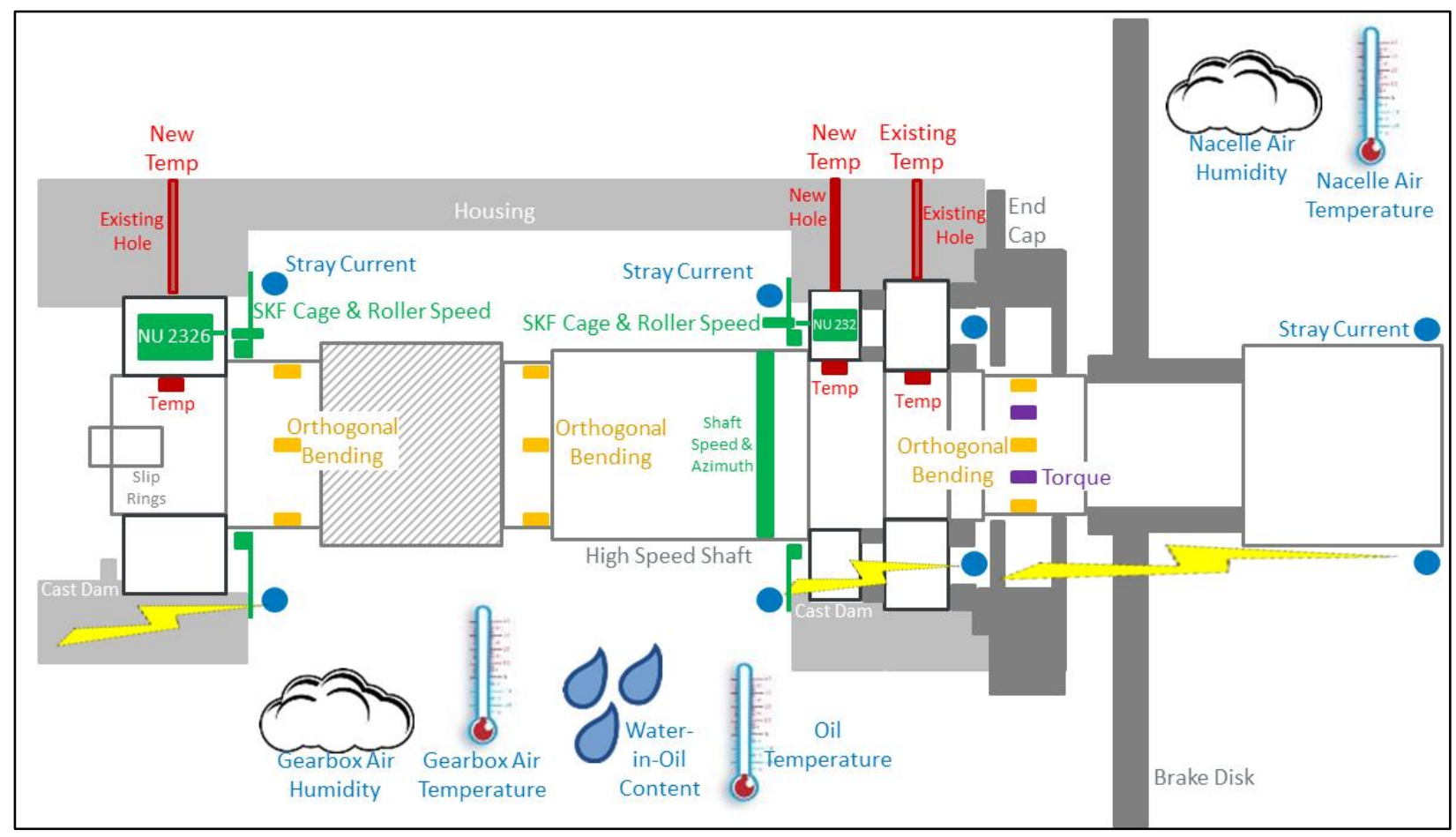

Figure 8. High-speed-shaft instrumentation package 


\section{Summary}

Axial cracking or WEC bearing failures continue to have a significant impact on the reliable operation of wind turbine gearboxes, and the root cause of WECs are still a subject of scientific debate. This study demonstrates a multipronged research approach by the U.S. Department of Energy to investigate axial crack failures from a system level to a material/tribological level. The current work shows a benchtop test methodology that successfully replicates WEC formation under controlled contact conditions, from which an energy-based criteria related to frictional heat is identified for WEC formation. This driver for WEC formation depends on the occurrence of sliding/skidding between the bearing rolling element and race. Evidence of this roller sliding is demonstrated at the system level through analysis of a gearbox dynamometer test with fieldrepresentative conditions. With a WEC formation methodology and operational understanding firmly established, the most cost-effective mitigation methods ranging from the part level (e.g., materials, coatings, lubricants, and microgeometry) to the system level (e.g., gearbox or bearing modifications, controller and converter software, mechanical torque-limiting devices) can be developed, tested, and verified. Future research activities will focus on assessing additional WEC drivers and identifying the physical processes at a material level. Additionally, in-field testing on a 1.5-megawatt turbine of high-speed-shaft bearings will be used to validate the actual conditions that could lead to axial crack bearing failures. 


\section{References}

1. Errichello, R., S. Sheng, J. Keller and A. Greco. 2011. Wind Turbine Tribology Seminar - A Recap (Technical Report). NREL/TP-5000-53754. National Renewable Energy Laboratory (NREL), Golden, CO (US). http://www.nrel.gov/docs/fy12osti/53754.pdf.

2. Luyckx, J. "Hammering Wear Impact Fatigue Hypothesis WEC/irWEA Failure Mode on Roller Bearings.” Wind Turbine Tribology Seminar, Broomfield, CO, 2011.

3. Hyde, S. "White Etch Areas: Metallurgical Characterization \& Atomistic Modeling." Wind Turbine Tribology Seminar, Argonne, IL, 2014.

4. Holweger, W. "Progresses in Solving White Etching Crack Phenomena." Gearbox Reliability Collaborative Annual Meeting, Golden, CO, 2014.

5. Gould, B. and A. Greco. 2016. Investigating the Process of White Etching Crack Initiation in Bearing Steel. Tribology Letters, 62 (26). doi: 10.1007/s11249-016-0673-z.

6. Gould, B. and A. Greco. "Impact of Transient Slide-to-Roll Ratio Events in the Wind Turbine Application.” Tribology Frontiers Conference, Chicago, IL, 2014.

7. Ruellan, A., F. Ville, X. Kleber, A. Arnaudon and D. Girodin. 2014. Understanding White Etching Cracks in Rolling Element Bearings: The Effect of Hydrogen Charging on the Formation Mechanisms. Journal of Engineering Tribology. 228 (11): 1252-1265. doi: $\underline{10.1177 / 1350650114522452 .}$

8. Gould, B. and A. Greco. 2015. The Influence of Sliding and Contact Severity on the Generation of White Etching Cracks. Tribology Letters. 60 (29). doi: 10.1007/s11249-0150602-6.

9. Scott, D., B. Loy and G.H. Mills. 1966. "Paper 10: Metallurgical Aspects of Rolling Contact Fatigue." Proceedings of the Institution of Mechanical Engineers, Conference Proceedings: doi: 10.1243/PIME_CONF_1966_181_303_02.

10. Evans, M.-H. 2016. An Updated Review: White Etching Cracks (WECs) and Axial Cracks in Wind Turbine Gearbox Bearings. Material Science and Technology. 32 (11): 1133-1169. doi: $\underline{10.1080 / 02670836.2015 .1133022 . ~}$

11. Gegner, J. 2011. Tribological Aspects of Rolling Bearing Failures. doi: $\underline{10.5772 / 20790}$.

12. Loos, J., I. Bergmann and M. Goss. 2016. Influence of Currents from Electrostatic Charges on WEC Formation in Rolling Bearings. Tribology Transactions. 59 (5): 865-875. doi: 10.1080/10402004.2015.1118582.

13. Backestrom, O. "Field Measurements for Wind Turbine Main Bearings." VDI Wissensforum, COWEC, 2013. 
14. Keller, J. and R. Wallen. 2015. Gearbox Reliability Collaborative Phase 3 Gearbox 2 Test (Technical Report). NREL/TP-5000-63693. National Renewable Energy Laboratory

(NREL), Golden, CO (US). http://www.nrel.gov/docs/fy15osti/63693.pdf.

15. Keller, J. and Y. Guo. 2016. Gearbox Reliability Collaborative Investigation of High-SpeedShaft Bearing Loads (Technical Report). NREL/TP-5000-66175. National Renewable Energy Laboratory (NREL), Golden, CO (US). http://www.nrel.gov/docs/fy16osti/66175.pdf.

16. Helsen, J., Y. Guo, J. Keller, and P. Guillaume. 2016. Experimental Investigation of Bearing Slip in a Wind Turbine Gearbox During a Transient Grid-Loss Event. Wind Energy. 19 (12): 2255-2269. doi: 10.1002/we.1979.

17. Volkmuth, M., K. Stadler and R. Heemskerk. "Slippage Measurements in Roller Bearings." Antriebstechnisches Kolloquium, Aachen, Germany, 2009.

18. Keller, J. 2016. GRC1.5: Uptower Gearbox Testing to Investigate Bearing Axial Cracking. NREL/PR-5000-65738. National Renewable Energy Laboratory (NREL), Golden, CO (US). http://www.nrel.gov/docs/fy16osti/65738.pdf. 